\title{
Interpretation of seismic data in the Wheeler domain: integration with well logs, regional geology and analogs
}

Friso Brouwer*, dGB-USA ; Geert de Bruin, dGB, Paul de Groot, dGB; David Connolly,dGB-USA

\section{Summary}

A workflow is presented where modern seismic interpretation techniques are integrated with well logs, regional geology and modern analogs, to show the advantage a multi-data/multi-disciplinary approach to geological interpretation. The seismic interpretation techniques are aimed at extracting specific geological information from the data using sequence stratigraphy interpretation and geomorphologic interpretation. This form of interpretation is very useful for cross-disciplinary communication and interpretation. In this extended abstract an outline of the techniques and workflow is given and then the workflow is illustrated with examples from a case study.

\section{Introduction}

Recently many new techniques for advanced geological interpretation of seismic data have been developed. For example various methods to aid interpretation of sequence stratigraphy and geomorphology (see de Bruin et al, 2007, Stark, 2004, Zeng et al 1998a and Zeng, et al 1998b) have been developed. In this study we use the method described by de Bruin et al (2007) Another example of supporting geological interpretation interpreting seismic data are the many different seismic attributes and neural network applications that have been developed to highlight different geological features in seismic data. An excellent overview of seismic attributes is provided by Chopra and Marfurt (2008), see Aminzadeh and de Groot (2004) on more information for meta-attributes and neural networks. Using these various techniques seismic can be transformed to more closely resemble a geological image of the subsurface. However, despite the all the possibilities that these new methods of seismic interpretation offer using them as a stand alone tool will underutilize their potential. Instead, these methods should be combined with, or constrained by "classical" methods of geological interpretation, such as the interpretation of the wells, modern and outcrop analogs and regional geological knowledge. Using the seismic methods mentioned before should increase the ease of such an integration, since the output data more closely resembles a true geological image, which will facilitate cross-disciplinary communication and interpretation.

Objective of this study is to develop a template for combining the latest seismic interpretation techniques with more established methods of seismic interpretation. Different aspects of this will be illustrated in a North Sea dataset, with its most prominent feature the presence of a prograding Tertiary delta complex.

\section{Workflow}

The following text and figure 1 give a brief overview of the workflow applied. The steps in the workflow are illustrated at the hand of the case-study described in the next section.

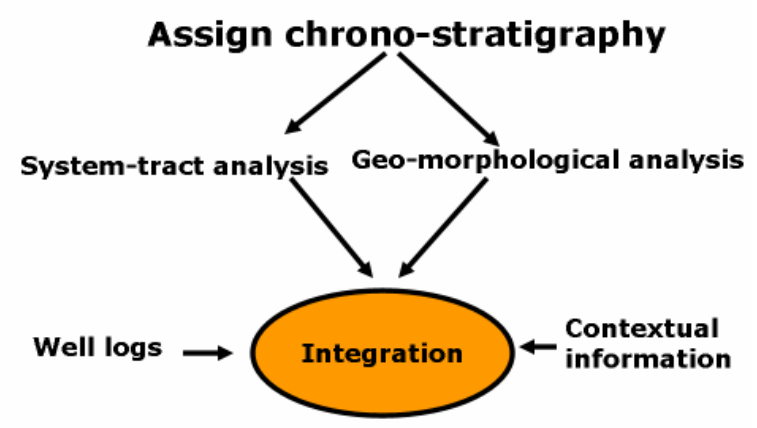

Figure 1: Workflow for transforming seismic data to the Wheeler domain, interpretation methods in the Wheeler domain and integration with other data.

We start the interpretation process -using the methods described by de Bruin et al (2007) - assigning data-driven chrono-stratigraphy on multiple $2 \mathrm{D}$ sections through the data and subsequently flattening these sections to seismic Wheeler diagrams. The objective is to better understand the sequence stratigraphy and arrive at a system tract interpretation. System tracts can be used to infer quality of source, seal and reservoir rocks.

The data-driven chrono-stratigraphy is created in two-step procedure. First the seismic dip is calculated. Using the seismic dip the chrono-stratigraphic horizons are tracked. Each horizon is assigned a chrono-stratigraphy index (relative geological time, 0 for the upper horizon). Horizons are terminated if they approach each-other closer then a thresh-hold value, so (angular) unconformities are automatically incorporated by the truncation of horizons. These truncations lead to the hiatuses seen in the seismic Wheeler diagram. Using the seismic Wheeler diagram together with the original seismic view we make a system tract interpretation on the multiple $2 \mathrm{D}$ sections. The multiple 2D sections will give a complete 3D understanding of the systems tracts. 


\section{Interpretation of seismic data in the Wheeler domain}

Using a number of horizons tracked on the major conformable and unconformable boundaries we also create a separate 3D model-based chrono-stratigraphy, this is equivalent to stratal slicing (see Zeng et al, 1998a and Zeng etal; 1998b). This 3D model driven chrono-stratigraphy is used to create a 3D seismic Wheeler space. Both raw seismic data and derived seismic attributes can be transformed and interpreted in the seismic Wheeler domain. As time slices in this Wheeler domain are approximate chrono-stratigraphic horizons, this procedure is equivalent to stratal slicing with the addition that unconformities are taken into account by the model. The raw seismic and attributes in 3D Wheeler space will display the preserved paleo-geomorphology within resolution of the seismic data. These displays can be used to refine the lithology prediction using the system tracts (laterally), find stratigraphic traps, but also support the system tract interpretation. The choice of attributes to use in this interpretation should (among others) depend on the seismic data, paleo-environment (e.g. deep sea vs coastal), current environment (e.g. depth of burial) and what geological features need to be highlighted.

At this point we have arrived at 2 "geological" representations of the seismic data. At this point further interpretation should occur integrated with "classical methods of interpretation" such as high resolution well data, regional geology and modern equivalents. Also further cross-disciplinary interpretation should be done in (personal) communication with colleagues specialized in fields such (sequence) stratigraphy, petrophysics, sedimentology, etc, as well as area-geologists. Using the system tract interpretation and seismic attributes in the Wheeler domain gives them a geological image of the data directly, to which they can immediately apply their (sometimes highly specialized) knowledge without having first to make the step from seismic data (of which they might not be that knowledgeable) to "geological observation".

\section{Case study}

The previously described workflow will be illustrated using a case study is located in the F3 block of the Dutch North Sea sector. The most prominent feature in the data is the presence of an advancing Tertiary delta complex, part of the giant Eridanos delta (Overeem, 2001). The input data available for this study are full stack seismic data and 4 well tracks with AI, PHIE and GR logs. The size of the seismic data set is $\sim 24 \mathrm{~km}$ in inline direction and $\sim 16 \mathrm{~km}$ in clossline direction, with a $25 \mathrm{mx} 25 \mathrm{~m}$ bin size. Though the interval studied does not have direct relevance for $\mathrm{HC}$ exploration, the study can be used as an analog in similar geological environments that have potential for valid $\mathrm{HC}$ plays. See figure 2 for an overview of the data.

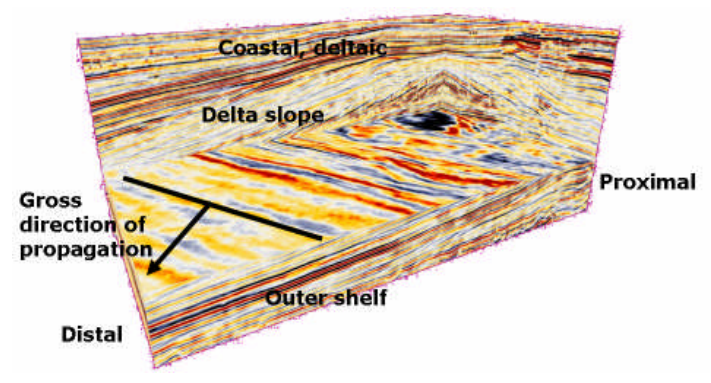

Figure 2: An impression of the seismic data under consideration. Some geological pointers are included.

Following the outline of the workflow for data-driven chrono-stratigraphy and system tract interpretation described in the previous section, in figure 3 we see the from top down: data-driven chrono-stratigraphy, a seismic Wheeler diagram derived from the chrono-stratigraphy and a system tract interpretation.. The hiatuses in the seismic wheeler diagram can be either erosional or condensed sections. Also the width of the area of deposition and the trends in deposition (aggrading, prograding, retrograding) are easily recognized in the seismic Wheeler diagram. Using these observations a system tract interpretation is created where the system tracts are defined between relative chrono-stratigraphy indices. 


\section{Interpretation of seismic data in the Wheeler domain}

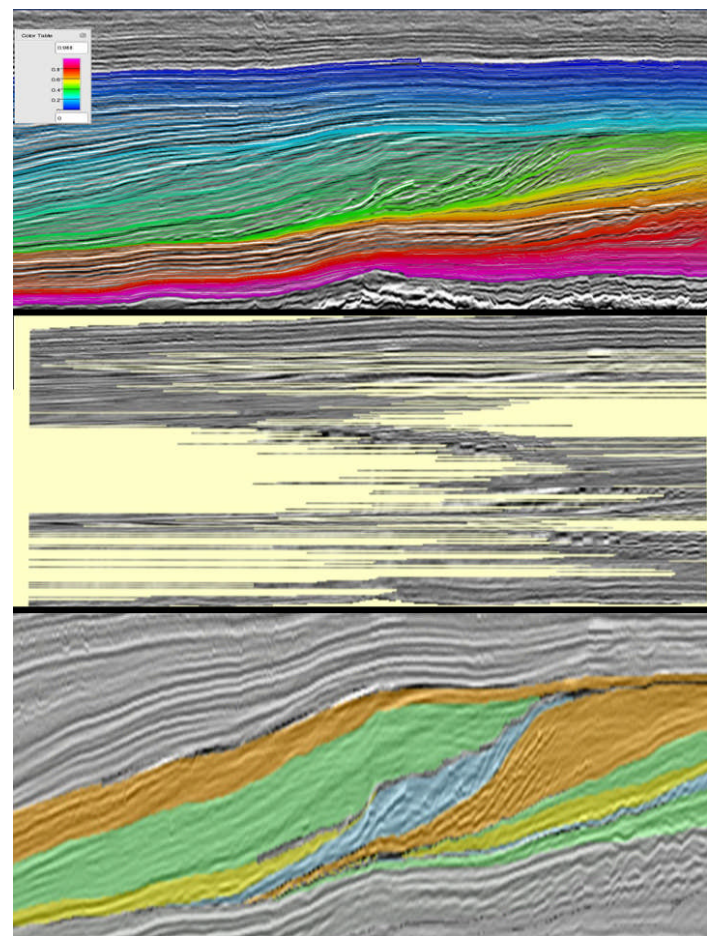

Figure3: Sequence illustrating the procedure to arrive at a system tract interpretation. The top images depicts a data driven chronostratigraphy. The midde shows a seismic Wheeler diagram created by flattening the chronostratigraphic horizons. the lower images shows the system tract interpretation, interpreted from a joint display of the upper and middle images.

Knowledge of the system tracts together with environment of deposition increases the confidence in predicting the presence of different elements necessary to make a successful HC play. In the following example, we have relative good sand in the wells correlating with the most distal part of an early low stand system tract (see figure 4). The early low stand is indeed a system tract where we expect sand to be arriving in the more distal (deeper water) regions of the sedimentary system, so the well log information and system tract interpretation are in agreement. On a horizon slice we display a discontinuity and segmentation attribute to make a geomorphological interpretation (see figure 5). From the observations on this horizon we can identify the sand as probably being "sand waves", a sedimentary feature also commonly observed in the modern North Sea (see figure 6). Identification of this feature as sand waves also gives an indication of paleowater depths, as these features -at least in the modern system- only occur in water depths smaller than $\sim 30 \mathrm{~m}$. Once identified as "sand waves", a feature characterized by different slopes on either side of the wave we use a geometric attribute -the lateral difference of polar dip- to visualize all sand waves and follow their development through geological time.

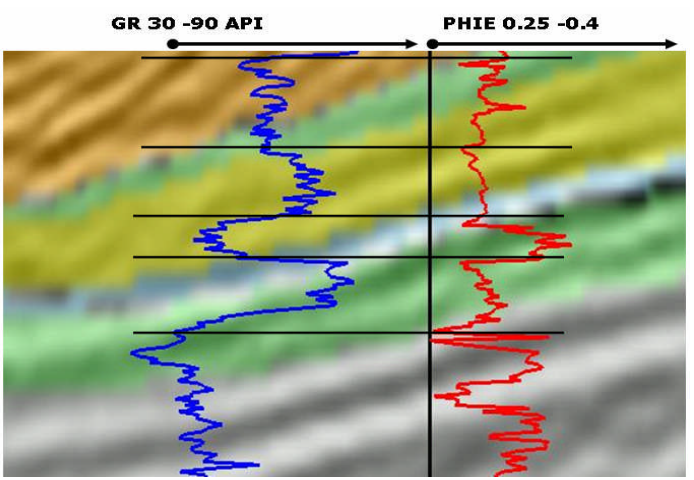

Figure 4: Gamma Ray and effective porosity well logs overlain on the system tract interpretation. The bleu system tract -early low stand-coincidences with a more sandy lithology.

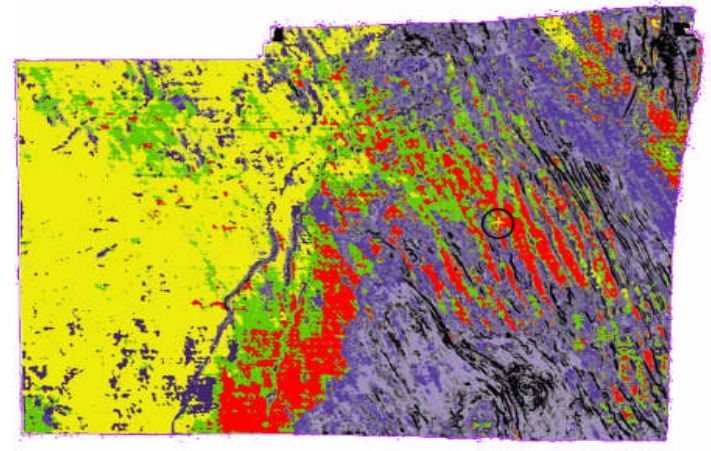

Figure 5: Discontinuity attribute (discontinuities in black) and waveform segmentation attribute (different waveforms have different colors). The well depicted figure 4 is located in the middle of the black circle. The corending of the attributes gives us an accurate image of the paleomorpholgy.

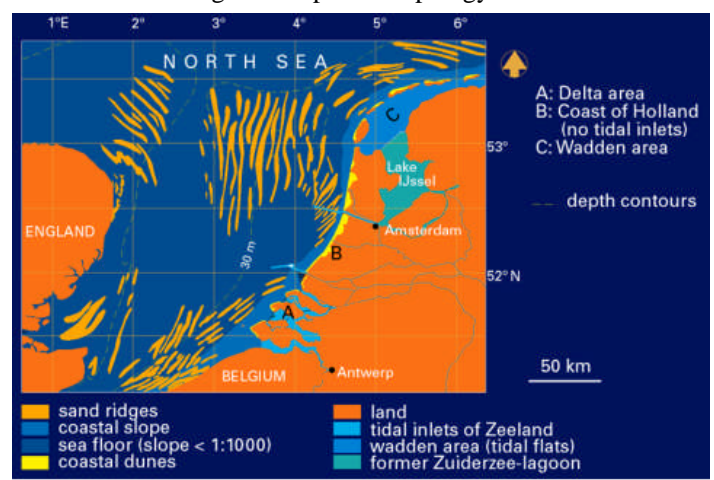

Figure 6::Map of similar "sand-waves" features in modern North Sea. 


\section{Interpretation of seismic data in the Wheeler domain}

For example, in figure 7 we see this attribute displayed on a horizon shallower then the horizon in image 5. The field of sand-waves has shifted significantly basin-ward, which is in agreement with the overall regressive nature of the early and late lowstand systems. From the attribute displays and seismic sections (not shown here) we can estimate the wavelength (300 to $1200 \mathrm{~m})$ and amplitude $(\sim 15 \mathrm{~m})$ of the sandwaves. Also in section view it seems that the longitudinal axis of the sand waves has a slight angle with the inferred paleo coastline, which is in agreement with modern data on sand wave features.

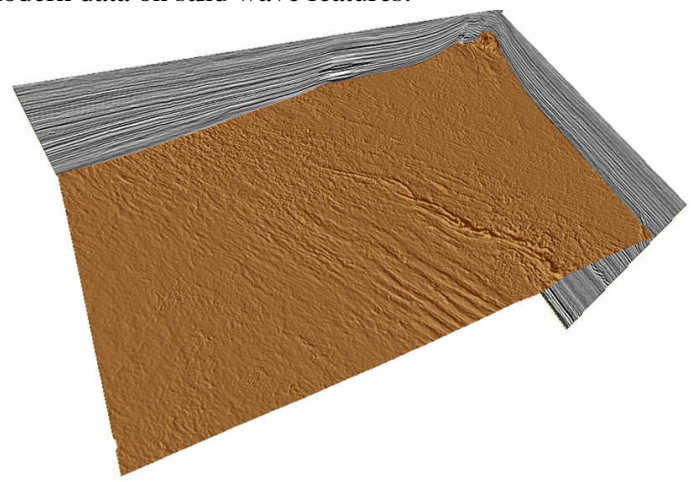

Figure 7: Lateral derivative of the polar dip. This attributes images features charatized by changing slopes. The image is taken on the a horizon about $\sim 100 \mathrm{~ms}$ above the horizon in figure 5. Again the sand-wave features are imaged well and have moved more basinward.

In addition to mapping certain facies, geomorphologic interpretation can also be used to support system tract interpretation. A typical example in deep water would be mapping the first lobes, indicating the onset of the early low stand system tract. In this case study we use geomorphology to map sub-aerial unconformities in the shallow water deposits above the delta complex. Here erosional surfaces are more or less angular conformable with sedimentary packages, hence not readily identifiable through typical "truncation" of reflectors. However, whenever there is aerial exposure, alluvial systems will start incising older packages, leaving abrupt lateral discontinuities in the reflectors. Logically we are going to use a discontinuity attribute to detect these incised sedimentary features. We process the discontinuity attributes and transform the attribute to the 3D model based Wheeler domain. In this domain we scan through the different chrono-stratigraphic levels. Geo-times that are characterized by marine sedimentation will create a relative blank view in the discontinuity attribute. Only some faulting and minor features such as slump scars will be visible. However, in periods with sub-aerial exposure a more expressive image will be present, representing incision and other alluvial and deltaic features. In figure 8 an example of the "submarine" expression of discontinuity is shown, in figure 9 an example of the "subaerial" expression of discontinuity is shown.

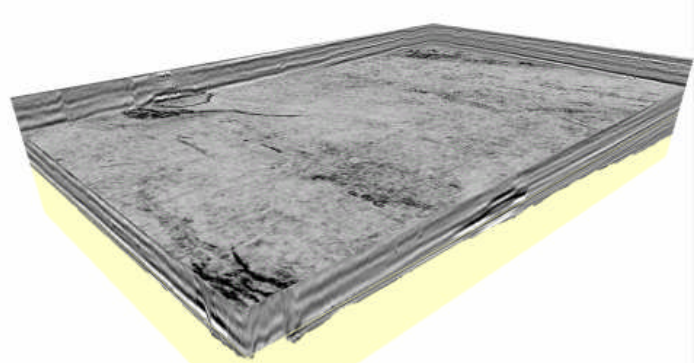

Figure 8: Displayed in grey-scales the discontinuity attribute-with black as discontinuity-. The display is on a time slice in the Wheeler-domain which is equivalent to a chronostratigraphic horizon. Notice the expression of the discontinuity attribute in what is inferred to be a submarine paleo-enviroment.

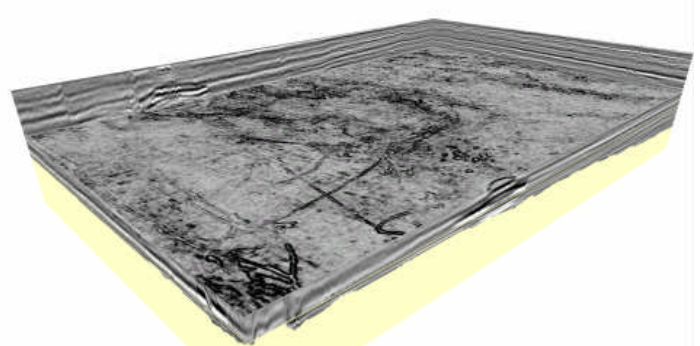

Figure 9: Displayed in grey-scales the discontinuity attribute-with black as discontinuity-. The display is on a time slice in the Wheeler-domain which is equivalent to a chronostratigraphic horizon Notice the expression of the discontinuity attribute in what is inferred to be a subaerial paleo-enviroment.

\section{Conclusions}

Modern seismic interpretation techniques for sequence stratigraphy and geomorphology should not be used as stand alone tools, but be integrated with classic methods such as (stratigraphic) interpretation from the wells logs, and imported geological understanding from modern and outcrop analogs as well as using constraints from regional geology.

Modern seismic interpretation techniques have to potential to serve as focus point for cross disciplinary discussion and interpretation.

The presented case study, shows the workflow with the before mentioned advantages. Though the case study does not have direct relevance for $\mathrm{HC}$ exploration it could serve as a seismic analog for more promising $\mathrm{HC}$ plays 


\section{EDITED REFERENCES}

Note: This reference list is a copy-edited version of the reference list submitted by the author. Reference lists for the 2008 SEG Technical Program Expanded Abstracts have been copy edited so that references provided with the online metadata for each paper will achieve a high degree of linking to cited sources that appear on the Web.

\section{REFERENCES}

Aminzadeh, F., and P. de Groot, 2004, Soft computing for qualitative and quantitative seismic object detection and reservoir property prediction: Neural network applications: First Break, 22, 49-54.

De Bruin, G., N. Hemstra, and A. Pouwel, 2007, Stratigraphic surfaces in the depositional and chronostratigraphic (Wheelertransformed) domain: The Leading Edge, 26, 883-886.

Chopra, S., and K. Marfurt, 2008, Emerging and future trends in seismic attributes: The Leading Edge, 27, $298-318$.

Overeem, I., G. J. Weltje, C. Bishop, and S. B. Kroonenberg, 2001, The late Cenozoic Eridanos delta system in the Southern North Sea Basin: A climate signal in sediment supply: Basin Research, 13, 293-312.

Stark, T. J., 2004, Relative geologic time (age) volumes-Relating every seismic sample to a geologically reasonable horizon: The Leading Edge, 23, 928-932.

Zeng H., M. M. Backus, K. T. Barrow, and N. Tyler, 1998, Stratal slicing, part I: Realistic 3D seismic model: Geophysics, 63, 502-513.

Zeng H., S. C. Henry, and J. P. Riola, 1998, Stratal slicing, part II: real seismic data: Geophysics, 63, 514-522. 